\title{
Os leopardos kafkianos de Moacyr Scliar: provocações, ditadura e bumor entre dois judeus
}

Eduardo Manoel de Brito I UFU

\begin{abstract}
Resumo: A partir do aforismo de Franz Kafka reproduzido por Moacyr Scliar em seu livro Os leopardos de Kafka, propomos uma reflexão sobre violência e humor entre os dois escritores, que têm em comum a origem e a tradição judaica. Primeiramente procuramos estabelecer os pontos de contato entre os escritores Moacyr Scliar e Franz Kafka, para, em seguida, enfocarmos a questão da violência expressa desde o ponto de vista mitico (no aforismo kafkiano) e desde o ponto de vista politico (no texto de Scliar). Reflexóes tais como os micropoderes (Michel Foucault) e conceitos de violência (Hannah Arendt) fundamentam nossa abordagem literária.

Palavras-chave: Moacyr Scliar, Franz Kafka, violência, humor.
\end{abstract}

Interpretações dos Leopardos de Kafka pelos personagens de Moacyr Scliar

Comecemos nossas considerações com o aforismo kafkiano utilizado por Moacyr Scliar em seu livro Os leopardos de Kafka: "Leopardos irrompem no 
templo e bebem até o fim o conteúdo dos vasos sacrificiais; isso se repete sempre; finalmente, torna-se previsível e é incorporado ao ritual." " O aforismo de Franz Kafka é de tal modo hermético que pode, paradoxalmente, ser interpretado de incontáveis modos. Apresentamos as interpretações do texto feitas pelos personagens criados por Moacyr Scliar:

a) Para um velho zelador na Altneuschule da cidade de Praga, o aforismo pode ser interpretado de dois modos: "Um quebra-cabeça, uma adivinhação?" (p. 52) e "[...] parece o resumo de um pesadelo" (p. 53). ${ }^{2}$

b) O personagem Ratinho, protagonista do romance, é quem faz o maior número de interpretações do aforismo. Num primeiro momento, ele considera o aforismo como sendo "a mensagem" (p. 54) e, no mesmo contexto inicial, tece o seguinte comentário: "Talvez o seu texto represente um novo estágio na literatura, um estágio que escapa ao alcance da maioria das pessoas" (p. 54). Buscando um entendimento mais profundo do texto, o protagonista faz uma longa reflexão de cada uma das partes dos termos do aforismo, confundido-o com uma mensagem cifrada que deveria ser recebida de um escritor judeu praguense comunista (p. 55-60). Desse modo, são estas as suas considerações:

1) "Talvez se tratasse de uma coisa simbólica";

2) "Talvez não se tratasse de leopardos verdadeiros";

3) "Admitindo os leopardos como revolucionários, havia, contudo, outro aspecto desconcertante: a frase final. A invasão dos felinos, sustentava Kafka, tornavase previsível";

4) "Em suma, os tais leopardos eram, no mínimo, bichos controversos";

5) "Templo, então. Agora estava pisando terreno mais concreto. Qualquer templo - católico, protestante, budista, judaico - era reduto da religião. E a religião, Marx tinha dito, é o ópio do povo";

1. Leoparden brechen in den Tempel ein und saufen die Opferkrüge leer; das wiederholt sich immer wieder; schließlich kann man es vorausberechnen und es wird ein Teil der Ceremonie. Disponível em: <http://www.kafka.org/ index.php?aphorismen>. Acesso em: 12 dez. 2008.

2. As citações foram extraídas de SCLIAR. Os leopardos de Kafka. A partir dessa citação serão indicadas as páginas da obra. 
6) "Ainda restava a palavra 'ritual'. Teria a ação revolucionária como objetivo perturbar, ou interromper, um ritual? Mas que ritual?". Por fim, o personagem, agora na presença do escritor Kafka, tece as seguintes considerações (p. 83-91): 1) "O texto? O texto é maravilhoso (...) Leopardos no templo (...) Maravilhoso (...) "Leopardos irrompem no templo" (...) Sem dúvida: maravilhoso (...)" e 2) "Aliás, Leopardos no templo me parece isso, uma mensagem dialética”.

c) O próprio Kafka, transformado em personagem por Scliar, faz algumas interpretações de seus textos: "A obscuridade (...). Não é isso? A obscuridade. É obscuro o texto. Sei disso. Todos os meus textos são assim, obscuros. É por isso que tenho dificuldade para publicá-los" (p. 85).

d) Para encerrar, já no fim do texto de Scliar e em Porto Alegre, o delegado Francisco (Dops de Porto Alegre), faz os seguintes comentários, buscando entender o aforismo: 1) "Mas que porra é essa, homem? Confesso que não entendi nada. Leopardos no templo? Que leopardos? Que templo?" (p. 111) e 2) "Não é? (...) Não é mesmo uma merda, um troço incompreensível? Leopardos no templo (...)Quem é que quer saber de leopardos no templo? Isso aí não tem pé nem cabeça. Para mim não passa de uma bobagem, de uma coisa maluca. Queres saber de uma coisa, Ratinho? Que se fodam esses leopardos no templo" (p. 112).

Como é possível perceber, o escritor Moacyr Scliar promove um número de interpretações do aforismo kafkiano que valoriza o caráter hermético do texto. E, desse modo, literaturiza ironicamente lugares-comuns da fortuna crítica kafkiana, pois é sabido que o autor tcheco foi interpretado de modos vários e considerado um escritor de textos herméticos, quando não ininteligíveis. Não é o caso, portanto, de os personagens encontrarem uma interpretação que dê conta de sua complexidade, mas de demonstrar o quanto o texto kafkiano se abre para interpretações várias - como obra aberta, para ficar com a expressão de Umberto Eco - e que, umas tantas vezes, podem até se chocar umas com as outras.

Para entendermos a relação entre o escritor brasileiro Moacyr Scliar e o autor tcheco Franz Kafka, de modo a fazer reflexões sobre a ironia e a violência presentes em ambos os escritores, façamos algumas considerações iniciais a partir de informações do livro Leopardos de Kafka e entrevistas concedidas pelo próprio Scliar. 


\section{Franz Kafka e Moacyr Scliar}

Moacyr Scliar publicou o seu Leopardos de Kafka em 2000, pela editora Companhia das Letras, na coleção Literatura ou Morte. A história pode ser assim resumida: um confuso comunista do Leste Europeu, o Ratinho, é incumbido de receber uma mensagem cifrada de um escritor judeu comunista na cidade de Praga. Perdendo todos os dados de seu contato, termina por receber um texto do próprio Franz Kafka, julgando ser ele o escritor procurado. O texto é o aforismo acima reproduzido.

Ratinho faz várias tentativas de interpretar o texto como sendo uma mensagem revolucionária cifrada. Fadados todos os seus esforços, descobre que cometeu um erro após outro. Pressionado pela situação europeia, muda-se para o Brasil e passa a residir em Porto Alegre. Já nos anos da ditadura civil-militar (19641984) tem um sobrinho preso no Dops, e o texto de Kafka volta a lume, provocando outras confusões. Ao final, em sonho, ele tem uma espécie de iluminação para o entendimento do texto, mas, então, já está à beira da morte.

Não cremos que seja necessário introduzir muitas informações sobre Franz Kafka, também porque no decorrer deste texto, o próprio Moacyr Scliar comentará alguns aspectos do autor tcheco. Basta, no momento, lembrarmos que Kafka foi introduzido no Brasil na década de 1940, por Otto Maria Carpeaux, e teve suas obras traduzidas para o português de modo sistemático e como projeto editorial apenas em meados da década de 1960 (a partir do francês e não do alemão original).

Franz Kafka é, ao lado de Proust e Joyce, considerado um dos escritores mais influentes do século 20. O adjetivo kafkiano, por exemplo, está dicionarizado em mais de cem idiomas, incluindo o português, e corresponde com grande alargamento semântico - à situação de desnorteio do personagem Josef K. e de outros personagens do escritor tcheco, lançados num mundo do qual eles não conhecem as regras e não possuem chaves de leitura.

Voltando a atenção para as relações Kafka-Scliar, assim se manifesta Moacyr Scliar, quando questionado se haveria afinidades entre ele e Kafka:

[Li as obras de Franz Kafka] por uma profunda afinidade. Eu buscava a imaginação, Kafka tinha a imaginação; eu buscava a metáfora, ele a tinha; eu buscava a economia, ele a tinha. Ah, sim, eu sou judeu ele também era. (...) 
Kafka fez minha cabeça. Eu queria escrever como ele. Tenho algumas coisas em comum com esse grande escritor, mas também coisas diferentes: sou brasileiro (vivo num país tropical), sou filho de emigrantes judeus da Europa Oriental, não vivi os conflitos que ele viveu. ${ }^{3}$

Durante o Congresso da Associação Brasileira de Literatura Comparada - Abralic - em julho de 2004, na cidade de Porto Alegre - , foi montada uma mesaredonda, com a presença do escritor, totalmente dedicada à sua obra. O próprio autor, ao final das comunicações, teceu comentários sobre sua produção literária e sobre os estudos críticos apresentados. Na ocasião, em conversa particular conosco e quando já levantávamos alguns aspectos para a escritura de nossa tese de doutorado, Moacyr Scliar referiu-se a alguns aspectos do golpe civil-militar de 1964 no Brasil, do qual, segundo ele, tomou conhecimento pelo rádio quando estava namorando num parque da cidade de Porto Alegre.

Suas primeiras leituras da obra de Franz Kafka se deram após os estudos universitários na Universidade Federal do Rio Grande do Sul, onde se formou em Medicina. Os primeiros textos de Franz Kafka lidos por Moacyr Scliar foram $A$ metamorfose e contos, em traduções para o português, provavelmente de Torrieri Guimarães. Apesar de Scliar afirmar que as traduções eram ruins e que ouvira críticas ao trabalho do tradutor, os textos suscitaram nele sensações de espanto e deslumbramento, e a pergunta que ele se fazia era: "Como pode alguém escrever com tal genialidade?" ${ }^{4}$

Apesar de Moacyr Scliar não se considerar, à época da ditadura civilmilitar brasileira, uma pessoa engajada na luta contra a mesma, afirma que se sentia oprimido e sufocado por ela, pois "tinha-se a impressão de que a ditadura ficaria para sempre" e, mesmo não fazendo parte de partidos ou de movimentos políticos, a ameaça fazia-se sentir diretamente, mesmo que fosse por meio da possibilidade de censura. Nesse sentido, existe algo da literatura kafkiana no momento político vivenciado no Brasil dos anos 1960 e 1970, pois a literatura kafkiana podia ser lida "como uma literatura de protesto, que se aplicava inclusive

3. Questionário enviado para Moacyr Scliar, escritor residente em Porto Alegre. Todas as perguntas foram incorporadas à tese de doutorado Quando a ficção se confunde com a realidade: as obras In der Strafkolonie/ $\mathrm{Na}$ colonia penal e Der Process/O processo de Kafka como filtros perceptivos da ditadura civil-militar brasileira.

4. Questionário enviado para Moacyr Scliar.

5. Questionário enviado para Moacyr Scliar. 
à ditadura brasileira". ${ }^{6}$ Mas tal relação é reiteradamente atenuada pelo escritor gaúcho na medida em que ele, num acintoso desprezo pelo autoritarismo e por tudo o que representou a ditadura, considera a ditadura civil-militar brasileira burra demais para ser kafkiana. As questões e as respostas a seguir ilustram tal ponto de vista:

Eduardo: Havia uma leitura "política" das obras de Kafka neste período? Moacyr Scliar: Isto não sei dizer. Acho que Kafka era muito distante de nossa realidade cultural para ser lido nesse sentido. García Marquez estava mais perto e ele personificou a literatura de protesto.

Eduardo: A ditadura brasileira iniciada nos anos sessenta pode ser chamada de kafkiana? Se sim, em quais aspectos?

Moacyr Scliar: Não, não pode ser chamada de kafkiana. Era burra demais para isso.

Eduardo: O senhor tem lembrança de algum episódio que poderia ser qualificado de kafkiano? Se sim, poderia descrevê-lo?

Moacyr Scliar: Não, os episódios que lembro são antes sinistramente ridículos do que kafkianos.

Eduardo: No seu livro Os leopardos de Kafka há muita ironia, mas o senhor relaciona a obra de Kafka com a ditadura brasileira. De onde veio a idéia para fazer tal relação? Algum evento (além dos fatos históricos narrados) ali descrito foi inspirado em algum fato histórico?

Moacyr Scliar: A idéia veio do tema da própria coleção: escritores envolvidos em crime e/ ou violência, mas o texto não foi inspirado por fato histórico. ${ }^{6}$

Eduardo: Que escritores brasileiros nos anos sessenta e setenta teriam se inspirado na obra de Franz Kafka, segundo a sua opinião como escritor? Moacyr Scliar: Murilo Rubião era muito próximo, mas ele dizia que nunca tinha lido Kafka.

Eduardo: Em que medida a literatura de Kafka ajuda a pensar o Brasil dos anos sessenta e setenta e o Brasil atual? Moacyr Scliar: Não ajuda muito. ${ }^{8}$

Questionado sobre a razão para se ler as obras de Franz Kafka hoje, o escritor gaúcho afirma simplesmente: "Porque é um grande escritor."

6. Questionário enviado para Moacyr Scliar.

7. A coleção organizada pela Companhia das Letras tem, sintomaticamente, o seguinte nome: Literatura ou morte.

8. Questionário enviado para Moacyr Scliar, escritor residente em Porto Alegre.

9. Questionário enviado para Moacyr Scliar, escritor residente em Porto Alegre. 
ainda que os textos de Kafka pudessem ser lidos como obras de protesto, que se aplicavam, inclusive, à situação brasileira nos anos 1970 e 1960, seu valor precípuo é a qualidade literária. E é exatamente sobre essa qualidade presente na configuração da realidade na obra de Kafka que repousa a diferença fundamental que a distingue da realidade da ditadura civil-militar brasileira, pois, embora as duas constituam narrativas, a primeira é considerada inteligente e elaborada e a segunda, burra e grosseira. Nesse sentido, ao ser questionado sobre uma possível contradição entre suas afirmações a esse respeito, Moacyr Scliar escreveu:

Aparentemente há uma contradição nas afirmativas, mas só aparentemente. Faltava à ditadura brasileira aquela sofisticação quase metafísica dos processos persecutórios kafkianos; a coisa era escarrada, grossa. Isto não impedia que intelectuais a rotulassem como kafkiana. Era um exagero literário. ${ }^{10}$

O exagero literário corresponde analogamente ao exagero de considerar a ditadura como nazista ou fascista (expressões também questionadas pelo professor e cientista político Paulo Sérgio Pinheiro, do Núcleo de Estudos da Violência da USP). Ao mesmo tempo, a rotulação "kafkiana" (criticada e minorada por Modesto Carone, que vê nos usos e abusos do adjetivo falta de justeza crítica) foi usada sem parcimônia, funcionando como uma espécie de lugar-comum na política brasileira. Apesar disso, havia algo de kafkiano na ditadura brasileira: uma falta de previsibilidade nas ações dos membros das forças policiais do Estado, uma burocracia que impedia o conhecimento amplo das estruturas de poder e um empoderamento de membros do baixo escalão que exerciam de forma truculenta o seu micropoder.

Ao ser questionado, ainda, sobre as relações entre sua obra Os leopardos de Kafka e a ditadura civil-militar brasileira, Scliar assim se manifesta:

Eu queria falar sobre Kafka e queria falar sobre o Brasil. Qual Brasil? O da ditadura militar, que marcou muito minha geração e é um tema a que volto constantemente. Juntar Kafka a esse contexto não foi difícil, mas, volto a te dizer, a ditadura foi "grossa" demais para ser considerada um exemplo de situação "kafkiana” (e acredito tê-lo demonstrado com aquele policial do Dops). ${ }^{11}$ Acho que Na colônia penal e O processo estão entre os textos mais kafkianos de Kafka, sobretudo, claro, O processo. Na colônia penal

10. Questionário enviado para Moacyr Scliar, escritor residente em Porto Alegre.

11. O escritor está referindo-se ao personagem do seu romance Os leopardos de Kafka, delegado Francisco (SCLIAR. Os leopardos de Kafka, p. 108-114). 
O eixo e a roda: $v .17,2008$

tem o componente da violência física, que também faz parte das ditaduras e que, de novo, escapa à pura situação kafkiana da qual o processo é o grande exemplo.

O limite e a beleza da arte literária residem aí, em não ser ela a pura transposição da realidade em palavras, mas no fato de possibilitar uma reelaboração do olhar, refinando algum tipo de percepção. Moacyr Scliar percebe que Oprocesso é o mais kafkiano dos textos de Franz Kafka exatamente porque aí, onde a violência é mais simbólica, há mais espaço para aquilo que ele considera ser literatura. Na colônia penal, com a aparência de relatório escrito por um cientista, contém a descrição da violência de maneira mais explícita, distando da construção literária mais refinada.

\section{Violência e humor em Moacyr Scliar e Franz Kafka}

Há uma combinação de fatores que liga, como o próprio Scliar testemunha, o escritor brasileiro e o tcheco; apesar disso, sob o peso específico da cultura e da cor local, há os fatores que os distanciam. Deixando de lado os aspectos já tratados pelo escritor brasileiro, aterei-me a dois aspectos presentes na literatura de ambos: a violência e o humor.

O livro de Scliar não possui nenhuma descrição de tortura, apesar de tratar, na parte final, de uma prisão à época do regime civil-militar brasileiro e, por isso, pode-se afirmar que é mais leve do que qualquer obra kafkiana. Ao menos atendo-nos aos romances - todos inacabados - de Franz Kafka e às suas novelas mais conhecidas, não nos vem à memória, de fato, nenhum texto kafkiano que possua a leveza bem-humorada apresentada por Moacyr Scliar em seu Leopardos de Kafka. Por outro lado, a presença da violência nas obras de Franz Kafka está muito além da descrição feita por Moacyr Scliar em seu livro. Assim, haveria uma diferença de atmosfera literária entre os dois autores, mesmo quando a violência paira sobre suas narrativas. Há um quixotismo à brasileira na narrativa de Scliar que não encontra espaço no ambiente de ar rarefeito dos personagens kafkianos, em especial se pensarmos em Der Process e In der Strafkolonie. Quando mencionamos o quixotismo à brasileira, pensamos especificamente nas confusões do antiherói de Scliar, o Ratinho, em sua busca de realizar ideais comunistas que sai sempre frustrada devido à sua incapacidade de organização e ao seu amadorismo.

O humor kafkiano é sombrio e, após os eventos funestos do século 20, não ajuda muito saber que Kafka ria até perder o ar quando fazia leituras 
públicas de seus textos. O riso de Kafka é algo que parece não mais se coadunar com esses textos que antecipam, literária e profeticamente, a execução sem sentido dos campos de concentração, das perseguições soviéticas, das ditaduras latinoamericanas e de tantos absurdos do século 20. Mas, ainda assim, há humor em Kafka: no acúmulo de detalhes que constrói suas narrativas impressionistas; nos vai-e-vens de Josef $\mathrm{K}$. infantilizado e tratando seu processo sem nenhum tipo de seriedade; na posição patética e ridícula do personagem do Oficial na colônia penal. Mas, mesmo aí, ri-se constrangido, como num riso do qual não se tem o direito pleno de achar algo engraçado.

Por outro lado, as situações descritas por Moacyr Scliar nos permitem risos mais livres. A incompetência bem-intencionada de Ratinho tem algo de chapliano e, portanto, nos simpatizamos com ele e, talvez por isso, conseguimos rir dele e, por que não, com ele. De fato, se Franz Kafka constrói personagens com os quais não queremos nos identificar (mesmo quando a história nos obriga a isso), Moacyr Scliar consegue criar um personagem atrapalhado, mas admirável em seus princípios e em sua luta pelo que considera bom e justo. Portanto, rir com ele é um ato até mesmo de solidariedade.

Talvez seja aí que o humor judeu encontra uma verve comum nos dois autores: ambos escrevem sobre o monstruoso com alguma intenção de riso. O problema é que o riso que estava sob os parágrafos de Kafka foi literalmente sepultado pelos eventos que se seguiram à sua morte e Moacyr Scliar carnavaliza o humor, mesmo quando sua intenção é homenagear Franz Kafka.

\section{Tornar risível o horror?}

Retomemos o aforismo kafkiano para refletir sobre o trabalho literário de tornar o horror risível: "Leopardos irrompem no templo e bebem até o fim o conteúdo dos vasos sacrificiais; isso se repete sempre; finalmente, torna-se previsível e é incorporado ao ritual." A ação dos leopardos no texto kafkiano corresponde, inicialmente, a uma profanação: não era a eles que estava destinado o conteúdo dos vasos sacrificiais, e a certeza disso está no verbo irromper, que remete à ideia de tomar de assalto algo. Em alemão, brechen também significa "quebrar" ou mesmo "infringir", sugerindo uma quebra de protocolos. A ação dos leopardos, portanto, implica um resultado que provém de um temor: eles irrompem e bebem até o fim o conteúdo dos vasos porque não podem ser impedidos. Imaginemos, portanto, que os frequentadores do templo (fiéis e sacerdotes) ficam acuados diante do irromper 
dos leopardos. E isso se dá por gerações ("se repete sempre") de forma que a surpresa das primeiras vezes (o irromper) é incorporada como se o ritual se cumprisse, também, com a entrada dos leopardos e sua ação no templo. O que vai dentro dos vasos sacrificiais (em alemão Opferkrüge) é um mistério para o leitor de Kafka.

Levando em conta a religião judaica, na qual ofertas sacrificiais são constantemente realizadas (menos nos dias atuais, devido à destruição do templo de Jerusalém), a ideia de uma intromissão de leopardos num rito sagrado - portanto personagens alheios à dimensão ritual em si, cuja repetição da ação se dá por tempos imemoriais - corresponderia a uma profanação. Isso não deixa de ser uma ácida ironia à própria ritualidade, que incorpora o que não entende, que se perde em passados imemoriais sem entender as origens das próprias ações.

Mas vejamos, pois, o reflexo desse aforismo no texto de Scliar. Há um ato de violência explícito na ação dos leopardos que, mesmo não sendo tão citado no decorrer do texto e das várias tentativas de interpretação, remete à potencialidade da violência gratuita, que termina por ser entendida como parte do processo religioso. No texto de Scliar, o religioso não entra em questão - o protagonista até aventa a hipótese de uma crítica à religião no aforismo, mas não a desenvolve profundamente -, mas sim o político. Entrecruzemos a violência simbólica de Franz Kafka e a violência política de Moacyr Scliar.

No caso da violência simbólica de Kafka, o peso recai na capacidade de amedrontar dos leopardos, que não são enxotados do templo e profanam o sagrado, seja devido à ameaça de seu vigor físico que impõe medo, seja devido a um fascínio diante do que se desenrola. No caso de Moacyr Scliar, a violência política se manifesta pela capacidade de amedrontar de um agente do Estado: o delegado Francisco. Um tem garras e vigor físico, o outro tem o seu micro poder ${ }^{12}$ elevado ao máximo devido à possibilidade de colocar em funcionamento a força de repressão violenta da ditadura brasileira. Comparáveis quanto ao resultado final - a capacidade de amedrontar - as duas realidades, porém, possuem muito de discrepante. O vigor ${ }^{13}$

12. O conceito de micro poder foi retirado da reflexão foucaultiana. FOUCAULT. Microfísica do poder.

13. Os conceitos de violência, poder e vigor foram utilizados a partir da reflexão arendtiana. Em Da violência, Arendt defende que a violência sempre se utiliza de instrumentos e faz uma diferenciação entre categorias que costumam ser tratadas em conjunto, mas que possuem diferenciações fundamentais, tais as que utilizamos em nosso artigo, contrapondo a violência do delegado Francisco em Scliar e o vigor dos leopardos em Franz Kafka. 
de um the vem da natureza; a violência do outro vem do uso de instrumentos e do poder que lhe são conferidos por uma estrutura autoritária e burocrática. A monstruosidade do ato de um tem algo de belo e mítico, fundada na força pura da natureza; a monstruosidade do outro se revela em sua grosseria e no primarismo de suas reflexões, fundada numa estrutura não natural, mas socialmente construída.

Rir, no primeiro caso, significaria postar-se ao lado dos críticos do ritualismo sem sentido de uma religião que perdera o contato com suas origens; rir, no segundo, seria a busca de desmontar o temor por intermédio de uma atitude desrespeitosa diante de uma autoridade, que, por ser ignorante, apenas consegue impor o medo ao invés de algum tipo de respeito. Afinal, a monstruosidade possuiria, em ambos os casos, aspectos risíveis.

\section{Considerações finais}

Da obra de Franz Kafka se afirmam muitas coisas, entre elas que o autor possuía um estilo expressionista de escrita, devido ao acúmulo de detalhes que colocava sob os olhos do seu leitor microrrealidades superrepresentadas. Os movimentos de Gregor Samsa em A metamorfose, somados à descrição de seu corpo transformado no de um inseto monstruoso, são bons exemplos do expressionismo kafkiano. O painel que se deixa entrever no aforismo, que mesmo curto permite um adentramento em realidades religiosas com uma série de ricas associações, também tem algo desse expressionismo. Certamente Moacyr Scliar soube articular as potencialidades do texto para construir os entrechos de sua narrativa.

Como fizemos questão de realçar, há uma composição literária em Scliar que dispõe o horror de uma invasão profana como contraposta ao horror de uma violência oficial praticada pelo Estado. Em ambos os casos, a articulação de forças desiguais serve para a intimidação seja de fiéis de uma religião, seja de ateus convertidos em leitores de obras de Franz Kafka. No caso de Scliar, cuja narrativa é mais presa a contextos históricos - europeus ou brasileiros -, a escrita do horror e do medo é mais chã, e o hermetismo do texto kafkiano serve para incursões bem-humoradas e risíveis.

Esse seria, portanto, um modo de leitura das imbricações da violência mítica na realidade política na relação entre os dois escritores judeus, cuja abordagem do monstruoso - seja na invasão profana de feras num ambiente religioso, seja na 
violência estúpida de um agente do governo ditatorial brasileiro - não deixa de ser feita com componentes nos quais é possível identificar um humor irônico e cortante.

Abstract: Starting from Franz Kafka aphorism in Moacyr Scliar's book Os leopardos de Kafka, we propose a reflection about violence and humor in the two writers, both of whom share Jew traditions and origin. First, we try to establish a common ground between Moacyr Scliar and Franz Kafka, so we can focus on the subject of violence from the mythic (Kafka) and political (Scliar) point of view. Our literary approach has among its basis reflections about "micro powers" (Michel Foucault) and violence concepts (Hannah Arendt).

Keywords: Moacyr Scliar, Franz Kafka, violence, humor.

$$
\text { Referências }
$$

ARENDT, Hannah. Da violência. Brasília: Ed. UnB, 1985.

CARPEAUX, Otto Maria. Franz Kafka e o mundo invisível. In: . A cinza do purgatório. Rio de Janeiro: Casa do Estudante do Brasil, 1942. p. 150-161.

ECO, Umberto. Obra aberta. São Paulo: Perspectiva, 1968.

FOUCAULT, Michel. Microfísica do poder. Rio de Janeiro: Graal, 1990.

KAFKA, Franz. A metamorfose. Trad. Modesto Carone. São Paulo: Companhia das Letras, 1997.

SCLIAR, Moacyr. Os leopardos de Kafka. São Paulo: Companhia das Letras, 2000.

SOUSA, Celeste Ribeiro; BRITO, Eduardo Manoel de; SANTOS, Maria Célia Ribeiro dos. A recepção da obra de Franz Kafka no Brasil. Pandaemonium Germanicum, São Paulo, n. 9, p. 227-254, 2005. 